\title{
Percutaneous transluminal angioplasty and stenting for recurrent carotid artery stenosis
}

Giuseppe Lanzino, M.D., Robert A. Mericle, M.D., Demetrius K. Lopes, M.D., Ajay K. Wakhloo, M.D., Ph.D., Lee R. Guterman, Ph.D., M.D., and L. Nelson Hopkins, M.D.

Department of Neurosurgery and Toshiba Stroke Research Center, School of Medicine and Biomedical Sciences, State University of New York at Buffalo, Buffalo, New York

Percutaneous transluminal angioplasty (PTA) and stenting has recently been proposed as an alternative to surgical reexploration in patients with recurrent carotid artery stenosis following endarterectomy. The authors retrospectively reviewed their experience after performing 25 procedures in 21 patients to assess the safety and efficacy of PTA with or without stenting for carotid artery restenosis.

The mean interval between endarterectomy and the endovascular procedure was 57 months (range 8-220 months). Seven arteries in five patients were treated by PTA alone (including bilateral procedures in one patient and repeated angioplasty in the same vessel in another). Early suboptimum results and recurrent stenosis in some of these initial cases prompted the authors to combine PTA with stenting in the treatment of 18 arteries over the past 3 years.

No major periprocedural deficits (neurological or cardiac complications) or death occurred. There was one periprocedural transient neurological event. A pseudoaneurysm of the femoral artery (at the access site) required surgical repair. In the 16 patients who each underwent at least 6 months of follow-up review, no neurological events ipsilateral to the treated artery had occurred after a mean follow-up period of 27 months (range 6-57 months). Three of five patients who underwent PTA alone developed significant (> 50\%) asymptomatic restenoses that required repeated angioplasty in one and PTA with stenting in two patients. Significant restenosis (55\%) was observed in only one of the vessels treated by combined angioplasty with stenting. Endovascular PTA and stenting of recurrent carotid artery stenosis is both technically feasible and safe and has a satisfactory midterm patency. This procedure can be considered a viable alternative to surgical reexploration in patients with recurrent carotid artery stenosis.

Key Words * angioplasty * carotid endarterectomy * carotid restenosis * stenting

With the routine use of noninvasive screening methods such as carotid artery Doppler ultrasonography, and longer patient survival as a result of more effective treatment of coexistent disease processes, recurrent postendarterectomy carotid artery stenosis is encountered with increasing frequency.[9] Surgical treatment of recurrent carotid artery disease poses significant challenges because dense scar tissue along the endarterectomy site renders the dissection more difficult and traumatic. In some cases, a standard carotid endarterectomy (CEA) is not technically feasible, and excision of the diseased segment followed by reconstruction with an interposition graft is necessary.[16] Thus, the morbidity and mortality rates related to surgery for carotid artery restenosis are significantly higher than those for primary carotid artery stenosis.[12,16]

Recently, angioplasty and stenting of the extracranial carotid artery has been suggested as a valid alternative to carotid artery reexploration in patients with recurrent disease.[1,2,19,20,22] In contrast to surgery, the presence of periarterial scarring does not pose a problem when performing the endovascular procedure because dissection is not required. Additionally, this approach requires only a few seconds of carotid artery occlusion and can be performed after induction of a local anesthesic, thereby avoiding the need for and risks of general anesthesia.

To assess the safety and efficacy of percutaneous transluminal angioplasty (PTA) with or without stenting of the extracranial carotid artery for recurrent stenosis, we reviewed our experience with 25 procedures in 21 patients. 


\section{Patient Population}

Between August 1993 and May 1998, 21 patients (15 men and six women; mean age 69 years, range 52-80 years) with postendarterectomy recurrent carotid artery stenosis underwent a total of 25 endoluminal revascularization procedures at our institution (Table 1). The mean interval between CEA and endovascular procedure was 57 months (range 8-220 months). Seven arteries in five patients were treated by PTA alone (including bilateral procedures in one patient and a repeated PTA in the same vessel in another) and 18 arteries in 18 patients by angioplasty combined with primary stenting (including two vessels previously treated by angioplasty alone). Hospital and office records as well as angiograms and noninvasive studies (Doppler ultrasonography and magnetic resonance angiography) obtained before the procedure and at follow-up examination were retrospectively reviewed. All except one of the original angiograms (Case 1, first procedure) were available for review. The degree of stenosis immediately before and at completion of angioplasty with or without stenting was calculated using the criteria developed by the North American Symptomatic Carotid Endarterectomy Trial to measure de novo stenosis.[18]

\begin{tabular}{|c|c|c|c|c|c|c|}
\hline \multicolumn{7}{|c|}{$\begin{array}{l}\text { TABLE } 1 \\
\text { DATA OF } 21 \text { PATIENTS WHO UNDERWENT PTA WITH OR WITHOUT STENTING } \\
\text { TID ARTERV STENOSIS AFTER CEA^ }\end{array}$} \\
\hline $\begin{array}{l}\text { Case } \\
\text { No. }\end{array}$ & $\begin{array}{l}\text { Age } \\
(y s),\end{array}$ & Presentation & $\begin{array}{l}\text { Irterval } \\
\text { from CEA } \\
{[m \infty]}\end{array}$ & $\begin{array}{l}\text { Procedure \& } \\
\text { Type of Stent }\end{array}$ & $\begin{array}{l}\text { Compli- } \\
\text { calion }\end{array}$ & Follow-Up Fesults \\
\hline 1 & $61, F$ & asym ptomatic & 10 & $\begin{array}{l}\text { angioplasty; repeated an- } \\
\text { gioplasty after } 9 \text { mos }\end{array}$ & none & $\begin{array}{l}57 \text { mos, asymptomatic; } 24-m o \text { angiogram; no } \\
\text { restenosis; } 48-m \text { o Doppler; no restenosis }\end{array}$ \\
\hline 2 & $74, M$ & asym ptomatic & $\begin{array}{l}\text { 8, It CA } \\
\text { 8, rt } \\
\text { Ca }\end{array}$ & $\begin{array}{l}\text { angioplasty It } \& \text { rt CAs; re- } \\
\text { peated rt angioplasty + } \\
\text { stent after } 16 \text { mos (Palmaz) }\end{array}$ & none & $\begin{array}{l}43 \text { mos, asymptomatic; It side, } 37-\text { mo Doppler, } \\
\text { mild }(\sim 50 \%) \text { stenosis stable; rt side, } 31-\text { mo } \\
\text { Doppler; no restenosis }\end{array}$ \\
\hline 3 & $77, M$ & TIAS & 104 & angioplasty & none & $\begin{array}{l}40 \text { mos, asymptomatic; } 33-\text { mo Doppler; no pro- } \\
\text { gression of mild stenosis }(\sim 50 \%)\end{array}$ \\
\hline 4 & $74, M$ & asym ptomatic & 23 & $\begin{array}{l}\text { angioplasty + stent } \\
(\text { Palmaz) }\end{array}$ & none & $\begin{array}{l}36 \text { mos, asymptomatic; } 34-m \text { o angiogram, } 45 \% \\
\text { restenosis (in between } 2 \text { stents); } 26-m o \\
\text { Doppler, increased velocity }\end{array}$ \\
\hline 5 & $64, M$ & asym ptomatic & 11 & angioplasty & none & $\begin{array}{l}39 \text { mos, asymptomatic; } 15 \text {-mo angiogram, mild } \\
\text { restenosis }(45 \%) 35 \text {-mo Doppler, no progres- } \\
\text { sion }\end{array}$ \\
\hline 6 & $80, F$ & TIAS & 21 & $\begin{array}{l}\text { angioplasty + stent } \\
\text { (Palmaz) }\end{array}$ & none & $\begin{array}{l}25 \text { mos, asymptomatic; } 21-m \text { o Doppler, no re- } \\
\text { stenosis; } 15 \text {-mo angiogram, no restenosis }\end{array}$ \\
\hline 7 & $57, F$ & TIAS & 29 & $\begin{array}{l}\text { angioplasty; repeated } \\
\text { angioplasty + stent } \\
\text { after } 14 \text { mos (Willstent) }\end{array}$ & none & $\begin{array}{l}21 \text { mos from 1st procedure; no ipsilat symp- } \\
\text { toms; recurrent contralat orthostatic Tins with } \\
\text { restenosis \& resolved after stenting; } 7 \text {-mo } \\
\text { Doppler; no restenosis }\end{array}$ \\
\hline 8 & $60, M$ & crescendo TIÁs & 47 & $\begin{array}{l}\text { angioplasty + stent } \\
\text { ('uballstent) }\end{array}$ & $\begin{array}{l}\text { Periprocedural } \\
\text { TIA; femoral } \\
\text { arteryPA }\end{array}$ & $\begin{array}{l}19 \text { mos, asymptomatic; } 13-\text { mo Doppler, no } \\
\text { restenosis }\end{array}$ \\
\hline 9 & $72, M$ & TIAS & $\begin{array}{l}20 \text { after } \\
\text { repeated } \\
\text { rt CEA }\end{array}$ & $\begin{array}{l}\text { angioplasty + stent } \\
\text { (Palmaz) }\end{array}$ & none & $\begin{array}{l}12 \text { mos, asym ptom atic; died of metastatic } \\
\text { prostate cancer progression; 3-mo Doppler, no } \\
\text { restenosis }\end{array}$ \\
\hline 10 & $72, M$ & TIAS & 55 & $\begin{array}{l}\text { angioplasty + stent } \\
\text { (uivallstent) }\end{array}$ & none & $\begin{array}{l}16 \text { mos, asym ptom atic; } 14-m o \text { Doppler, } \\
\text { increased velocity; statle from previous study } \\
6 \text { mos earlier }\end{array}$ \\
\hline
\end{tabular}




\begin{tabular}{|c|c|c|c|c|c|c|}
\hline$\dagger 11$ & $52, M$ & asym ptomatic & 156 & $\begin{array}{l}\text { angioplasty + stent } \\
\text { (Palmaz) }\end{array}$ & none & $\begin{array}{l}16 \text { mos, asym ptom atic; } 12 \text {-mo Doppler, no } \\
\text { restenosis } 6 \text {-mo angiogram, no restenosis }\end{array}$ \\
\hline 12 & $74, M$ & asym ptomatic & 13 & $\begin{array}{l}\text { angioplasty + stent } \\
\text { (Palmaz) }\end{array}$ & none & $\begin{array}{l}17 \text { mos, asym ptom atic; } 17 \text {-mo angiogram, } \\
\text { mild }(40 \%) \text { instent stenosis } 13 \text {-mo } \\
\text { Dopder, increased velocity }\end{array}$ \\
\hline$\ddagger 13$ & $68, F$ & asym ptomatic & 180 & $\begin{array}{l}\text { angioplasty + stent } \\
\text { (uvallstent) }\end{array}$ & none & $\begin{array}{l}15 \text { mos, asym ptom atic; } 15 \text {-mo angiogram, } \\
55 \% \text { stenosis immediately distal to stent } \\
8 \text {-mo Doppler, increased velocity }\end{array}$ \\
\hline 14 & $69, \mathrm{~F}$ & TIA & 15 & $\begin{array}{l}\text { angioplasty + stent } \\
\text { ('Wall stent) }\end{array}$ & $\begin{array}{l}\text { surgical closure of femoral } \\
\text { arteriotomy wi patient on } \\
\text { continuous hepinfusion }\end{array}$ & $\begin{array}{l}9 \text { mos, asym ptomatic; 7-mo Doppler, no } \\
\text { restenosis }\end{array}$ \\
\hline 15 & $71, M$ & asym ptomatic & 18 & $\begin{array}{l}\text { angioplasty + stent } \\
\text { (Uudalstent) }\end{array}$ & none & $\begin{array}{l}6 \text { mos, asym ptomatic; 6-mo Doppler, no } \\
\text { restenosis }\end{array}$ \\
\hline 16 & 66, M & asymptomatic & 30 & $\begin{array}{l}\text { angioplasty + stent } \\
\text { (Integra) }\end{array}$ & none & $\begin{array}{l}6 \text { mos, asym ptomatic; 6-mo Doppler, no } \\
\text { restenosis }\end{array}$ \\
\hline 17 & $80, \mathrm{~F}$ & asymptomatic & 220 & $\begin{array}{l}\text { angioplasty + stent } \\
\text { (Uulalstent) }\end{array}$ & none & (less than 6 mos revie w) \\
\hline 18 & $71, \mathrm{M}$ & minor stroke & 27 & $\begin{array}{l}\text { angioplasty + stent } \\
\text { (uvilstent) }\end{array}$ & none & (less than 6 mos revie w) \\
\hline 19 & $69, M$ & asym ptomatic & 120 & $\begin{array}{l}\text { angioplasty + stent } \\
\text { (udillstent) }\end{array}$ & none & (less than 6 mos revie w) \\
\hline 20 & $79, M$ & TIAS & 75 & $\begin{array}{l}\text { angioplasty + stent } \\
\text { (Uudallstent) }\end{array}$ & none & (less than 6 mos revie w) \\
\hline 21 & 55 , M & $\begin{array}{l}\text { amaurosis } \\
\text { fugax }\end{array}$ & 6 & $\begin{array}{l}\text { angioplasty + stent } \\
\text { (Udall stent) }\end{array}$ & none & (less than 6 mos revie w) \\
\hline
\end{tabular}

\section{Management Protocol}

Follow-up bilateral carotid artery Doppler ultrasonography was performed after each endovascular procedure. Although attempts were made to schedule these studies at 6 and 12 months and yearly thereafter, patient compliance with this protocol varied.

However, each of the 16 patients included in the follow-up analysis (except the patient in Case 9, who underwent only a 3-month follow-up Doppler study) underwent a 6-month follow-up Doppler study. The interval from the last procedure to the most recent Doppler and/or angiographic study is indicated in Table 1. Patients were also evaluated at office visits (usually 1 month and then yearly postprocedure). If Doppler ultrasound demonstrated increased peak systolic velocity (> $200 \mathrm{~cm} / \mathrm{seconds}$ ) or rapid progression of velocity increase from a previous study, cerebral angiography was performed. Cerebral angiography was also performed if patients presented with signs and/or symptoms suggestive of recurrent cerebrovascular disease. In May 1998, the 16 patients with at least 6 months of follow up, or their immediate family members, were interviewed by telephone to obtain information on current health and neurological status, as well as any neurological, cardiac, or other medical events that may have occurred subsequent to their last visit. For one patient (Case 13), follow-up information that included Doppler studies and a copy of the follow-up angiogram was obtained from the referring physician.

\section{Indications for PTA Alone or Combined With Primary Stenting}

Doppler studies were used for screening, and PTA was considered only in those patients with angiographic confirmation of significant recurrent stenosis.

Clinical presentation consisted of transient ischemic attacks (TIAs) ipsilateral to the affected side in seven of the 10 symptomatic patients. One of these patients (Case 8) presented with crescendo TIAs, was admitted to the hospital, received treatment with intravenous heparin, and underwent revascularization on a semiurgent basis (Fig. 1). Of the three remaining symptomatic patients, the first (Case 7), with an angiographically demonstrated right internal carotid artery (ICA) occlusion and a high-grade left ICA stenosis, presented with right hemispheric TIAs associated with orthostasis; the second patient had suffered ipsilateral amaurosis fugax; and the third patient suffered an ipsilateral minor stroke. 


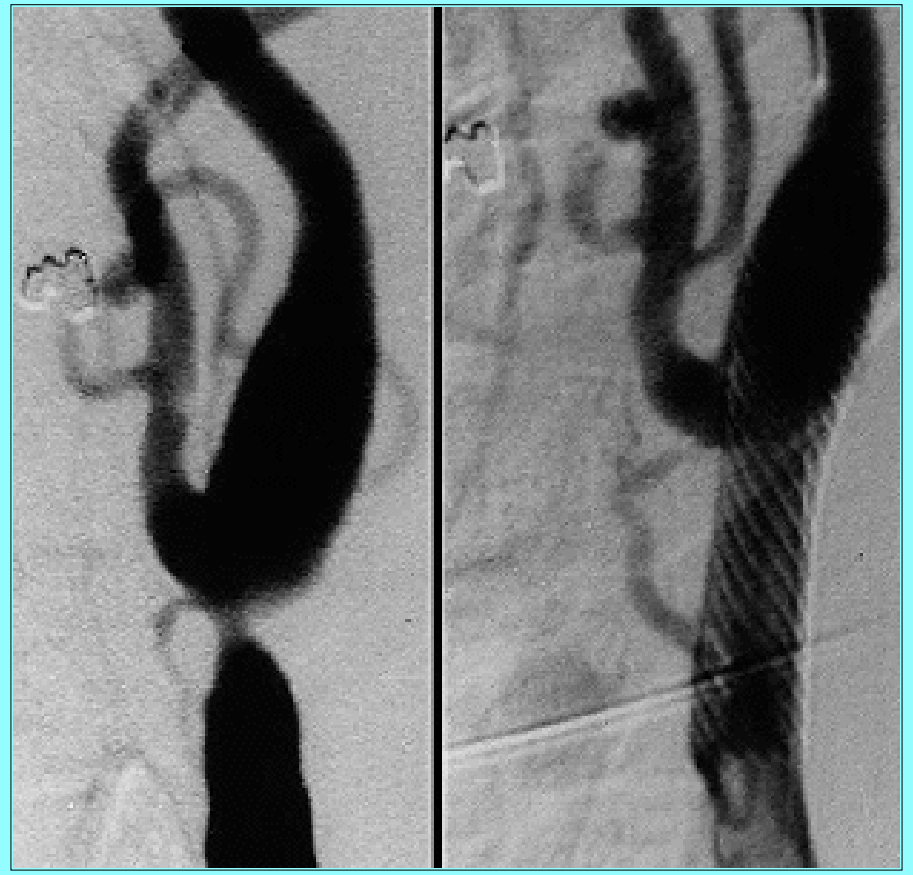

Fig. 1. Case 8. This 60-year-old man with crescendo TIAs presented 47 months after undergoing left CEA. Left A: Left common carotid artery angiogram showing moderate to severe restenosis involving the distal common carotid artery at the level of the bifurcation. Right B: After angioplasty and stenting, angiogram demonstrated resolution of the stenosis. This patient suffered the only periprocedural neurological event observed in this series. He also developed a femoral artery pseudoaneurysm at the access site that required surgical repair. Nineteen months after the procedure, he remains symptom free. A Doppler study performed 13 months after angioplasty with stenting showed no evidence of restenosis.

Of the 11 asymptomatic patients, nine underwent angioplasty with or without stenting because of angiographic evidence of restenosis that had shown progression on serial Doppler studies (Fig. 2). Prophylactic revascularization of a high-grade recurrent stenosis was performed before coronary artery bypass grafting for unstable angina in Case 11. In addition to previous CEA, the patient in Case 13 also had a history of previous radiation treatment of the neck and recurrent thyroid carcinoma; she underwent angioplasty with stenting for recurrent asymptomatic carotid artery stenosis before reexploration for her recurrent thyroid cancer. Despite angiographically demonstrated stenosis of approximately $60 \%$, two patients in Cases 5 and 15 received treatment because of rapid progression of Doppler velocity increases.

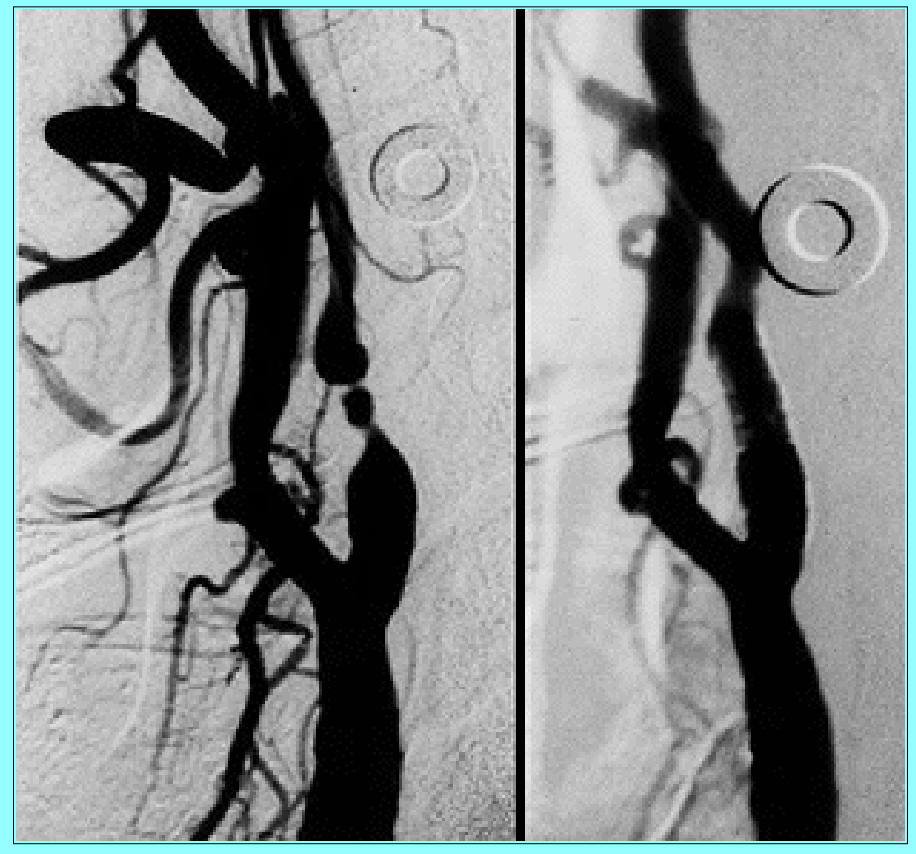

Fig. 2. Case 16. Angiographic studies. This 66-year-old man with a history of diabetes mellitus presented 30 months after CEA for evaluation of a high-grade asymptomatic restenosis (left) that had shown progression on serial Doppler studies. He underwent uneventful angioplasty and stenting of the restenotic lesion (right). A 
follow-up Doppler study 6 months later showed no evidence of restenosis, and the patient remains asymptomatic.

\section{Technique and Perioperative Care}

Before admission, each patient received oral ticlopidine (250 mg twice daily) and aspirin therapy (325 mg daily). All procedures were performed after induction of local anesthesia at the puncture site and neuroleptanalgesia. Percutaneous arterial access was obtained through the femoral artery. Early in our experience, we routinely placed a transvenous cardiac pacemaker preoperatively, if the lesion was located near the carotid sinus. More recently, we placed a femoral venous sheath, with a pacemaker readily available. This precautionary measure facilitates the treatment of rare malignant bradycardia or asystole during balloon inflation procedures. A 5000-unit bolus of heparin is administered at the beginning of the procedure after femoral catheterization, and the intraoperative activated clotting time is maintained at approximately 300 seconds throughout the procedure. Prior to angioplasty alone or combined with stenting, local thrombolytic therapy was routinely attempted using 100,000 units of urokinase (Abbokinase; Abbott Laboratories, Chicago, IL) infused through a microcatheter placed proximal to the lesion. We believe that any newly formed thrombus, which would be dissolved by the urokinase, is more likely to dislodge than old, organized plaque that is unaffected by the urokinase.[10] Intravenous atropine $(0.5 \mathrm{mg})$ is usually administered prior to balloon angioplasty, except in patients with severe coronary artery disease in whom cardiac stimulation is considered inadvisable.

In our early experience, we performed primary angioplasty for uncomplicated lesions and proceeded with stent placement only when the improvement in vessel diameter following angioplasty alone was considered unsatisfactory. However, because of our own experience and because of more recent data advocating primary stenting, $[1,2,19,20,22]$ we subsequently deploy stents in all patients in whom evidence of restenosis is found.

Before inflating the balloon for the PTA procedure, vessel diameters were measured proximal and distal to the lesion in the two perpendicular planes, generally in the anteroposterior and lateral projections. The length of the diseased vessel segment was also measured. The type and size of stent were chosen based on these measurements.

Following the procedure, all patients were admitted to the intensive care unit for overnight observation, and the heparinization was allowed to reverse spontaneously in most patients. At the time of discharge, patients were advised to take aspirin if they had undergone angioplasty alone; oral ticlopidine for 1 month was added to the regimen if stenting was also performed.[4, 17] In each patient who underwent PTA and stenting, a baseline Doppler study of the treated artery was performed on postprocedural Day 1.

\section{RESULTS}

The clinical characteristics and follow-up findings of these 21 patients are summarized in Table 1. Using North American Symptomatic Carotid Endarterectomy Trial criteria,[18] in the 24 of 25 treated vessels for which detailed angiographic documentation was available for review, the mean stenosis was $75 \%$ pre- and $9 \%$ immediately postangioplasty with or without stenting; the mean percentages were $68 \%$ and $40 \%$ in patients who underwent angioplasty alone, and $77 \%$ and $-3 \%$ in those who underwent angioplasty combined with stenting, respectively. The median hospital stay was 1 day.

\section{Complications}

There were no periprocedural permanent neurological or cardiac deficits or deaths. One patient (Case 8) suffered a TIA shortly after the procedure but showed no new changes on cranial computerized tomography scanning. The same patient also developed a femoral artery pseudoaneurysm that required surgical repair. One patient (Case 14) required direct surgical closure of the access site because we did not want to suspend the continuous infusion of intravenous heparin therapy given her recent recurrent TIAs.

\section{Clinical Follow-Up and Midterm Patency}

No transient or permanent neurological events ipsilateral to the treated vessels developed in the 16 patients who each underwent at least 6 months of follow-up evaluation (mean 27 months, range 6-57 months). One patient (Case 10, Fig. 3), who had undergone PTA and stenting for right carotid artery restenosis and also had a known $95 \%$ contralateral stenosis, suffered one episode of left amaurosis fugax 3 months after the endovascular procedure. He underwent attempted left CEA, but his ICA was found to be occluded at surgery. One patient (Case 11) with a known high-lying cervical vertebral artery stenosis experienced a possible vertebrobasilar TIA. Endovascular revascularization of the vertebral artery stenosis could not be accomplished because of the high-lying lesion. 


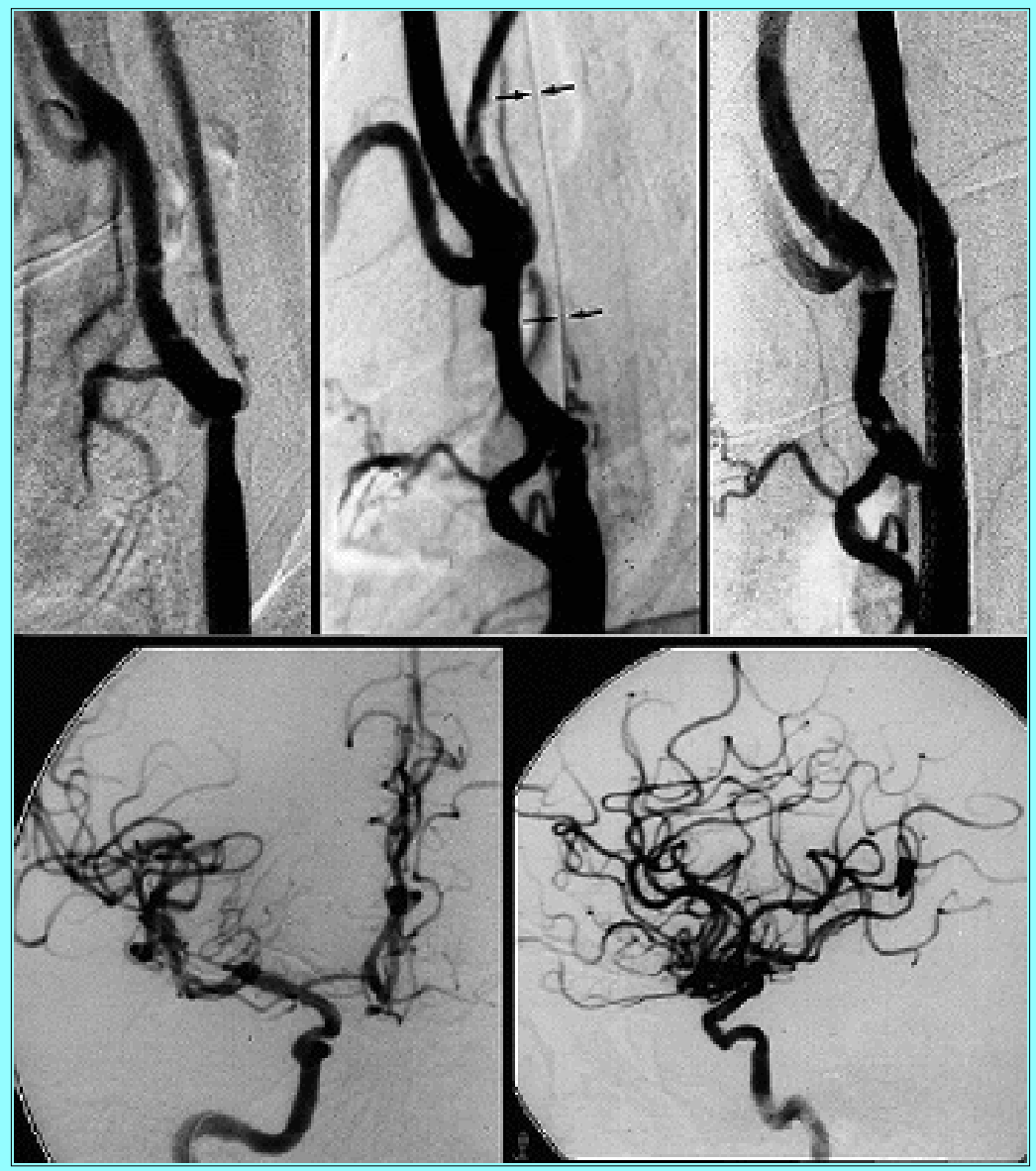

Fig. 3. Case 10. Angiographic studies.This 72-year-old man presented with right hemispheric TIAs and a recurrent high-grade ipsilateral stenosis (upper left) 55 months after CEA. The stenotic lesion was so severe that passing a microguidewire (upper center, arrows) through the lesion caused an asymptomatic occlusion of the ICA. Uneventful angioplasty and stenting of the lesion was performed with restoration of flow through the ICA (upper right). The filling defect in the proximal external carotid denotes an intraluminal clot, which did not have any clinical significance. No major vessel dropout is evident on the final intracranial angiograms (lower left, anteroposterior view; lower right, lateral view). This patient had a known, asymptomatic high-grade contralateral stenosis, and 2 months later suffered an episode of left amaurosis fugax. A left CEA was attempted, but the artery was found to be occluded at surgery. Sixteen months after angioplasty and stenting, the patient is asymptomatic, although a follow-up Doppler study performed at 14 months showed evidence of increased velocities at the transition zone where two stents were overlapped.

In the five patients (including one bilateral angioplasty, one repeated angioplasty; seven vessels total) who underwent angioplasty alone early in our treatment experience, significant $(>50 \%)$ asymptomatic restenosis occurred in each of three vessels (Cases 1, 2, and 7). These were treated by repeated PTA in Case 1 and repeated PTA with stenting in Cases 2 and 7.

Of the 18 patients (18 vessels) who underwent PTA and stenting, Doppler studies were obtained in 13 at least 3 months postprocedure. Significant asymptomatic restenosis (55\%) immediately distal to the stent was angiographically demonstrated 15 months postprocedure in one patient (Case 13). A retrospective review of this patient's immediate postprocedure angiogram revealed that the lesion had not been completely covered by the stent (in addition to previous endarterectomy, she had also received cervical radiation treatment for thyroid cancer). Mild, asymptomatic restenosis (45\% in Case 4 and $40 \%$ in Case 12 ) occurred in two more patients. In the patient in Case 4, this occurred at the point where two stents overlapped. In the patient in Case 12, mild restenosis occurred within the stent and showed spontaneous improvement on successive angiograms, from $49 \%$ at 5 months postprocedure to $40 \%$ at 17 months postprocedure. In the patient in Case 10, Doppler ultrasonography showed increased velocities at the transition zone where two stents overlapped. This Doppler finding was not considered to be clinically significant (peak systolic velocity $3 / 4200 \mathrm{~cm} /$ second), and no follow-up angiogram was obtained. Repeated Doppler study 6 months later had not revealed any further velocity increase.

\section{DISCUSSION}

The reported incidence of recurrent carotid artery stenosis following CEA varies from 4\% to 22\%[9] and is dependent on the interval from CEA, the criteria adopted to define carotid artery restenosis, and whether routine surveillance using Doppler 
ultrasonography is performed after CEA. According to the time interval after the original CEA, two types of recurrent lesions have been described. Early restenosis is due to a fibroproliferative lesion, whereas a true recurrent atherosclerotic lesion is seen 2 or more years following the initial surgery.[3]

Surgical treatment of recurrent carotid artery stenosis is technically more difficult.[16] Scar tissue at the old arteriotomy site makes the dissection more traumatic; also, a true cleavage plane between the recurrent lesion and the vessel wall is often missing or ill defined.[16] Thus, cranial nerve injuries and neurological complications are more frequent than in the CEA procedure for the treatment of primary stenosis.[12,16] Because of these limitations, the major complication rate of repeated CEA approaches $10 \%$ or higher, even when performed by the most experienced surgeons.[16]

In 1983, Tievsky, et al.,[20] proposed that percutaneous carotid angioplasty was a safe alternative to CEA in patients with recurrent stenoses. The main advantage of the procedure in this subgroup of patients is that scarring along the surgical site does not pose a problem because dissection is not required. With PTA alone, however, several problems remain unsolved,[1,2] and more recently, intravascular stents have been utilized to support the dilation obtained when angioplasty is performed. After successful angioplasty, the placement of endovascular stents prevents occlusion if postangioplasty dissection occurs,[1] decreases the risk of emboli resulting from friable vessel lining, and improves long-term patency by providing a rigid endoluminal support that resists the vascular recoil observed with the more fibrous recurrent lesions.[1,22]

Although the results of some early studies have suggested that significant neurological deficits are associated with PTA and stenting for the treatment of recurrent carotid artery stenosis, $[1,2,6]$ our results demonstrate that endovascular revascularization can be safely performed in this patient subgroup. Only one periprocedural transient neurological deficit and no permanent deficits or death resulted from the 25 procedures. Similar favorable results were reported by Yadav, et al.,[22] who, in a series of 22 patients undergoing 25 angioplasty and stenting procedures for carotid artery restenosis, encountered only one minor stroke (a complication rate of $4 \%$ per treated artery).[21] The apparent discrepancies among series can be explained by the different techniques performed. In one series, for example, direct carotid artery puncture was often utilized to gain access,[6] whereas in the other series, stenting was only performed if complications (occlusion or dissection) occurred after angioplasty.[1] Like Yadav, et al., we routinely use femoral access and currently deploy a stent after performing angioplasty to treat the restenotic lesions. Our routine use of intraarterial thrombolytic therapy before angioplasty might also explain the low incidence of neurological complications in our experience compared to that of others.[1,6] We believe that any newly formed thrombus, which would be dissolved by urokinase, is more likely to dislodge than old organized plaque that is unaffected by the urokinase.[10] Because no vessel dissection is required from the endovascular route, there are no cranial nerve deficits associated with the procedure.

In evaluating the results of angioplasty and stenting for the treatment of primary or recurrent carotid artery disease, it is important to consider that these procedures are often performed in high-risk patients with severe coexistent disease processes. Despite this, the nonneurological morbidity rate in our study as well as others[1,6,7,11,13,15,21] is very low, and no perioperative cardiac events were encountered. This observation supports the opinion that endovascular revascularization is a safe procedure in patients with severe coexistent diseases. It can be easily performed after induction of local anesthesia with minimal intravenous sedation, thereby avoiding the risks of a general anesthesic. Additionally, only a few seconds of carotid artery occlusion are required; thus, it can be safely performed in patients with contralateral severe stenoses or occlusions[20] (as in our Cases 7 and 10) and in those with coexistent intracranial disease. Care must be exercised in those patients with peripheral vascular disease in whom the prolonged use of large femoral sheaths for access and periprocedural anticoagulation therapy can lead to the occurrence of access-site complications. In our series, one patient developed a femoral pseudoaneurysm that required surgical repair. Newer closure techniques should decrease the incidence of femoral complications.

An additional advantage of the endovascular approach is that thromboembolic complications occurring during the procedure can be promptly recognized. Patients are awake, and their neurological status can be closely monitored. Any neurological change from the baseline is promptly recognized. In some patients, vessel occlusion can be visualized on angiography before the manifestation of clinical symptoms. When occlusive complications occur, in many cases they can be efficaciously reversed by intraarterial chemical and/or mechanical thrombolytic therapy (G Lanzino, et al., unpublished data) or by immediate stent deployment,[2] as seen in our Case 10 (Fig. 3).

The patency rate after PTA and stenting was satisfactory, albeit not ideal. Of the seven arteries in five patients originally treated with angioplasty alone, three patients (Cases 1,2, and 7) developed significant progressive restenoses. The addition of stent placement seems to improve the patency rate by allowing a greater immediate improvement in the vessel diameter. Even after stent placement, however, a mild to moderate degree of in-stent stenosis can be observed, secondary to neointimal hyperplasia in the first few months postprocedure. It is possible that the tendency to experience restenosis is more marked in patients who undergo treatment for postendarterectomy stenosis than in those with primary carotid artery disease because the vessel-recoil 
forces are much stronger in the first group due to the often fibrotic nature of the lesions. Additionally, it has been suggested that patients who suffer early recurrent carotid artery stenosis may possess an inherent susceptibility to excessive neointimal hyperplasia.[3]

We observed asymptomatic significant (> 50\%) restenosis immediately distally to the stented segment in one patient (Case 13) after PTA and stenting. In this case, retrospective review of the immediate postprocedure angiogram revealed that the lesion had not been completely covered after stent deployment. In one other patient (Case 4) a mild (45\%) asymptomatic restenosis occurred at the point at which two stents overlapped. True in-stent mild (40\%) restenosis was encountered only in one patient (Case 12). Interestingly, in this patient the degree of stenosis improved spontaneously from 49 to $40 \%$ on angiograms obtained 1 year apart. This phenomenon of delayed improvement in vessel diameter after an initial worsening of the degree of stenosis has been already well characterized after angioplasty alone in the carotid artery[5] and after angioplasty and stenting in the coronary arteries.[14] Although a longer follow-up period and a larger number of patients are required to draw definitive conclusions, the results of our series suggest that PTA and stenting provide protection from neurological symptoms because no patient has experienced new neurological events ipsilateral to the treated territory after a mean follow-up period of 27 months.

\section{CONCLUSIONS}

Revascularization of recurrent carotid artery stenosis can be safely achieved through the endovascular approach. Endoluminal revascularization for recurrent carotid artery stenosis has a satisfactory midterm patency rate and also seems to provide protection from further neurological events. Thus, carotid artery stenting can be considered a viable alternative to surgical reexploration in patients with recurrent carotid artery stenoses. Significant potential for improvement of the devices used exists. The catheters, balloons, and stent technologies used in these preliminary studies were all adapted from coronary or peripheral vascular applications; none was specifically designed for use in the extracranial carotid artery. Future developments in stent technologies may produce customized devices that have an antiproliferative function as well (that is, stents may find application as vehicles for local drug delivery in an attempt to decrease the incidence of restenosis).[8]

\section{Acknowledgments}

The authors thank Dr. Rafael Rodriguez-Mercado for providing a clinical update and copies of the follow-up angiogram and Doppler study reports in Case 13, and Paul H. Dressel for the preparation of photographs.

\section{References}

1. Bergeron P, Chambran P, Benichou H, et al: Recurrent carotid disease: will stents be an alternative to surgery? J Endovasc Surg 3:76-79, 1996

2. Bergeron P, Rudondy $\mathrm{P}$, Benichou $\mathrm{H}$, et al: Transluminal angioplasty for recurrent stenosis after carotid endarterectomy. Int Angiol 12:256-259, 1993

3. Callow AD: Recurrent stenosis after carotid endarterectomy. Arch Surg 117:1082-1085, 1982

4. Colombo A, Hall P, Nakamura S, et al: Intracoronary stenting without anticoagulation accomplished with intravascular ultrasound guidance. Circulation 91:1676-1688, 1995

5. Crawley F, Clifton A, Markus H, et al: Delayed improvement in carotid artery diameter after carotid angioplasty. Stroke 28:574-579, 1997

6. Diethrich EB, Ndiaye M, Reid DB: Stenting in the carotid artery: initial experience in 110 patients. J Endovasc Surg 3:42-62, 1996

7. Dorros G: Complications associated with extracranial carotid artery interventions. J Endovasc Surg 3:166-170, 1996

8. Eeckhout E, Kappenberger L, Goy JL: Stents for intracoronary placement: current status and future directions. J Am Coll Cardiol 27:757-765, 1996

9. Frericks H, Kievit J, van Baalen JM, et al: Carotid recurrent stenosis and risk of ipsilateral stroke: a systematic review of the literature. Stroke 29:244-250, 1998

10. Guterman LR, Budny JL, Gibbons KJ, et al: Thrombolysis of the cervical internal carotid artery before balloon angioplasty and stent placement: report of two cases. Neurosurgery 38:620-624, 1996

11. Guterman LR, Wakhloo AK, Hopkins LN: Endovascular cervical carotid revascularization. J Neurosurg 88:390A, 1998 
(Abstract)

12. Hertzer NR, O'Hara PJ, Mascha EJ, et al: Early outcome assessment for 2228 consecutive carotid endarterectomy procedures: the Cleveland Clinic experience from 1989 to 1995. J Vasc Surg 26:1-10, 1997

13. Iyer SS, Roubin GS, Yadav JS, et al: Angioplasty and stenting for extracranial carotid stenosis: multicenter experience. Circulation 94 (Suppl 1): 1-58, 1996 (Abstract)

14. Kimura T, Yokoi H, Nakagawa Y, et al: Three-year follow-up after implantation of metallic coronary-artery stents. New Engl J Med 334:561-566, 1996

15. Lanzino G, Hopkins LN: Carotid artery stenosis: the case for stenting. Clin Neurosurg 45 (In press, 1998)

16. Meyer FB, Piepgras DG, Fode NC: Surgical treatment of recurrent carotid artery stenosis. J Neurosurg 80:781-787, 1994

17. Morice MC, Aubry P, Benvéniste E, et al: The MUST trial: acute results and six-month clinical follow up. J Invas Cardiol 10:457-463, 1998

18. North American Symptomatic Endarterectomy Trial Steering Committee: North American Symptomatic Endarterectomy Trial: methods, patient characteristics, and progress. Stroke 22:711-720, 1991

19. Théron J, Raymond J, Casasco A, et al: Percutaneous angioplasty of atherosclerotic and postsurgical stenosis of carotid arteries. AJNR 8:495-500, 1987

20. Tievsky AL, Druy EM, Mardiat JG: Transluminal angioplasty in postsurgical stenosis of the extracranial carotid artery. AJNR 4:800-802, 1983

21. Yadav JS, Roubin GS, Iyer S, et al: Elective stenting of the extracranial arteries. Circulation 95:376-381, 1997

22. Yadav JS, Roubin GS, King P, et al: Angioplasty and stenting for restenosis after carotid endarterectomy. Initial experience. Stroke 27:2075-2079, 1996

Manuscript received October 1, 1998.

Accepted in final form November 18, 1998.

Address reprint requests to: Giuseppe Lanzino, M.D., Department of Neurosurgery, State University of New York at Buffalo, 3 Gates Circle, Buffalo, New York 14209-1194. 